\title{
УСТАНОВЛЕНИЕ НЕОБХОДИМОСТИ ПРОВЕДЕНИЯ КАПИТАЛЬНОГО РЕМОНТА МНОГОКВАРТИРНОГО ДОМА: АНАЛИЗ И ПРЕДЛОЖЕНИЯ
}

\section{ESTABLISHING THE NEED FOR MAJOR REPAIRS OF AN APARTMENT BUILDING: ANALYSIS AND SUGGESTIONS \\ S. Kartavov Yu. Sidorov}

Summary: The article is devoted to the study of the issue of establishing the need for major repairs of common property in apartment buildings. The analysis of the legislation of the subjects of the Russian Federation on the regulation of the procedure for establishing such a need is carried out. Some contradictions of Federal norms in this sphere of legal relations are revealed. Changes to the established values of the maximum level of physical wear of structural elements of apartment buildings for their inclusion in regional capital repair programs are proposed, and the need to establish common Federal criteria for making decisions on capital repairs is shown. The importance of monitoring the technical condition of apartment buildings is argued.

Keywords: capital repairs of common property in an apartment building, the authority to establish the need for major repairs, capital repair facility, the maximum level of physical wear of structural elements of an apartment building, the legislation of the subjects of the Russian Federation, commission for determining the need for major repairs.
Картавов Сергей Александрович

соискатель, Уральский институт управления филиал Российской академии народного хозяйства и государственной службы при Президенте Российской Федерации, г. Екатеринбург

kartavovs@yandex.ru

Сидоров Юрий Вадимович

К.ю.н., дочент, Уральский институт управления филиал Российской академии народного хозяйства и государственной службы при Президенте Российской Федерачии, г. Екатеринбург

yuriy.sidorov@ui.ranepa.ru

Аннотация: Статья посвящена исследованию вопроса об установлении необходимости проведения капитального ремонта общего имущества в многоквартирных домах. Проведен анализ законодательства субъектов Российской Федерации по регулированию порядка установления такой необходимости. Выявлены некоторые противоречия федеральных норм в указанной сфере правоотношений. Предложены изменения в установленные значения предельного уровня физического износа конструктивных элементов многоквартирных домов для их включения в региональные программы капитального ремонта, показана необходимость установления единых федеральных критериев для принятия решений о капитальном ремонте. Аргументирована важность результатов мониторинга технического состояния многоквартирных домов.

Ключевые слова: капитальный ремонт общего имущества в многоквартирном доме, объект капитального ремонта, полномочие по установлению необходимости капитального ремонта, предельный уровень физического износа конструктивных элементов многоквартирного дома, законодательство субъектов Российской Федерации, комиссия по установлению необходимости капитального ремонта.
$\mathrm{O}$ дним из актуальных вопросов организации капитального ремонта многоквартирных домов, который проводится по правилам IX раздела Жилищного кодекса Российской Федерации [1] (далее по тексту - ЖК РФ), является вопрос установления необходимости такого ремонта. Его актуальность обусловлена тем обстоятельством, что от решения данного вопроса зависит не только комфорт, но и безопасность условий, в которых проживают российские граждане, сделавшие свой выбор в пользу многоквартирного дома. Кроме этого, важно учесть, что капитальный ремонт оплачивают собственники помещений соответствующего многоквартирного дома «из своего кармана» [2], что дает им повод надеяться на эффективное расходование уплаченных ими денежных средств, даже несмотря на то, что оплачивают они капитальный ремонт принадлежащего им имущества - общее имущество в многоквартирном доме принадлежит собственникам помещений такого многоквартирного дома на праве общей долевой собственности [3].

Объективно установить необходимость проведения капитального ремонта какой-либо сложной вещи не просто, что объясняется ее неоднородностью, наличием в ее составе множества простых вещей с различными свойствами, а также наличием связей между ними. Указанные обстоятельства приводят к тому, что эксплуатация любой сложной вещи будет приводить к различной степени износа входящих в ее состав компонентов, а потому трудно провести однозначную границу между двумя ее состояниями: когда эксплуатация сложной вещи еще возможна и когда ее эксплуатация уже нежелатель- 
на, поскольку небезопасна.

Общее имущество в многоквартирном доме, рассматриваемое как объект капитального ремонта, является сложной вещью по той причине, что правила, регламентирующие организацию выполнения такого ремонта, предусматривают капитальный ремонт не отдельных элементов общего имущества из числа установленных в части 1 статьи 36 ЖК РФ, а предусматривают виды работ по капитальному ремонту (части 1, 2 статьи 166 жК РФ). Таким образом, объектом капитального ремонта при любом виде работ всегда является комплекс (совокупность) множества отдельных элементов, из которых состоят, к примеру, крыша многоквартирного дома, или его лифт, или внутридомовая инженерная система его электроснабжения.

Данный вывод подтверждает также само понятие «капитальный ремонт объекта капитального строительства» [4], которое означает замену и (или) восстановление как самих строительных конструкций, систем и сетей инженерно-технического обеспечения объектов капитального строительства, так и элементов, из которых состоят такие конструкции, системы и сети. В отношении несущих строительных конструкций - замена и (или) восстановление их отдельных элементов.

При прочих равных условиях, сокращение межремонтных сроков в отношении общего имущества снизит его аварийность и повысит безопасность, но приведет к увеличению расходов на капитальный ремонт; обратная ситуация - сокращение расходов - приведет к увеличению межремонтных сроков, что повысит риск аварийности и, соответственно, снизит степень безопасности. Указанное обстоятельство, безусловно, усложняет объективную оценку необходимости капитального ремонта, при которой важно найти разумный баланс между затратами собственников помещений и надлежащим техническим состоянием их общего имущества, обеспечивающим безопасные и комфортные условия проживания.

Полномочие по определению порядка установления необходимости проведения капитального ремонта общего имущества в многоквартирном доме ЖК РФ закрепил за субъектами Российской Федерации [5]. Данный факт сам по себе уже означает наличие неоднородности в критериях и подходах, применяемых для установления такой необходимости, в пределах Российской Федерации.

Тем не менее, на федеральном уровне в 2014 году принят документ рекомендательного характера, адресованный органам государственной власти субъектов Российской Федерации - приказ Минстроя России от 04.08.2014 № 427/пр «Об утверждении методических рекомендаций установления необходимости проведения капитального ремонта общего имущества в много- квартирном доме» [6] (далее по тексту - Методические рекомендации).

Согласно Методическим рекомендациям при определении необходимости проведения капитального ремонта следует применять Ведомственные строительные нормы 58-88 (р) «Положение об организации и проведении реконструкции, ремонта и технического обслуживания жилых зданий, объектов коммунального и социально-культурного назначения» [7] (далее по тексту - ВСН 58-88 (р)) и Ведомственные строительные нормы 53-86 (р) «Правила оценки физического износа жилых зданий» (далее по тексту - ВСН 53-86 (р)) [8].

ВCH 58-88 (р) содержит такой ориентир как «минимальная продолжительность эффективной эксплуатации элементов зданий и объектов» ВСН приводит его с оговоркой «рекомендуемое» и содержит указание на возможность корректировать эту продолжительность, а также методику оценки физического износа жилых зданий, признаки такого износа и примерный состав работ.

Согласно вышеуказанным ВСН, при достижении уровня физического износа 61-80\% таких конструктивных элементов многоквартирного дома как фундамент, перекрытие, крыша, кровля, система горячего водоснабжения, система холодного водоснабжения, система отопления, система канализации, система электрооборудования, указанные конструктивные элементы и системы подлежат полной замене. Более жесткие требования к уровню физического износа ВСН предъявляют для стен - они подлежат полной замене при достижении уровня физического износа 61-70\%.

Закрепленные ВСН предельные уровни физического износа обращают на себя внимание при их сопоставлении с некоторыми нормами ЖК РФ. В частности, согласно пункту 1 части 2 статьи 168 ЖК РФ, в соответствии с нормативным правовым актом субъекта Российской Федерации в региональную программу капитального ремонта могут не включаться многоквартирные дома, физический износ основных конструктивных элементов (крыша, стены, фундамент) которых превышает 70\%, из чего следует вывод о необходимости включения в программу домов, чей показатель равен или менее 70\% (при условии соблюдения иных критериев для включения в программу).

В итоге может возникнуть следующее противоречие: в том случае, если физический износ стены многоквартирного дома составляет 70\%, то эту стену по нормам ВСН требуется полностью заменить, а по нормам ЖК РФ достаточно выполнить ее капитальный ремонт [9].

Содержание понятия «капитальный ремонт объекта капитального строительства», на что было указано выше, 
раскрывает Градостроительный кодекс Российской Федерации в пункте 14.2 статьи 1, проанализировав которое, можно сделать вывод о том, что капитальный ремонт в отношении несущих строительных конструкций не предполагает их полную замену, а предполагает замену исключительно их отдельных элементов [10].

Учитывая данное обстоятельство, представляется целесообразным снизить до 60\% предельный уровень физического износа, установленный ЖК РФ для включения в программы капитального ремонта, в целях, прежде всего, устранения противоречия с аналогичными показателями $\mathrm{BCH}$, поскольку капитальный ремонт не предполагает, в частности, возможность полной замены стены многоквартирного дома, а ВСН «рекомендует» заменить стену. Тем не менее, независимо от того, рекомендательная норма или обязывающая, именно цифры в данном случае должны предопределять решение того или иного субъекта: полностью заменить стену или выполнить ее капитальный ремонт.

В качестве отступления от хода рассуждения считаем возможным обратить внимание на следующий аспект рассматриваемого вопроса. Любое измерение сопровождается погрешностью, размер которой необходимо учитывать при фиксации результатов проведенного измерения. И чем «грубее» будет измерение, тем больше будет размер погрешности. Возможно, именно по этой причине, массу грузовиков измеряют, как правило, в тоннах, а ювелирных украшений - в граммах. Размер погрешности при измерении массы последних в тоннах вызвал бы уместный вопрос о точности такого измерения.

В связи с этим, учет размера погрешности измерения уровня физического износа такого конструктивного элемента как стена многоквартирного дома, особенно важен для корректного установления ее технического состояния, поскольку значение уровня физического износа стены, полученное в результате соответствующего измерения, может отличаться от его истинного значения по причине как свойств стены, так и особенностей измерений. По этой причине результаты таких измерений должны автоматически учитывать определенную долю погрешности (например, плюс-минус 1-5\%). В итоге, документально зафиксированный уровень физического износа 70\%, не всегда будет означать, что этот уровень непременно равен 70\%, а, скорее всего, будет означать, что полученный в результате измерения уровень физического износа стены многоквартирного дома составляет 70\% с оговоркой «плюс-минус 5\%», то есть может быть равен и $65 \%$, и $75 \%$.

Данное отступление еще раз подтверждает целесообразность снижения предельного уровня физического износа, установленного ЖК РФ для включения в региональные программы капитального ремонта. Износ на уровне 70\% позволяет «пройти» в программу капитального ремонта, но учет погрешности измерения в диапазоне даже в 2\%, уже ставит такую возможность под сомнение.

Следующий вопрос, на который хотелось бы обратить внимание, заключается в следующем. Решение о необходимости проведения капитального ремонта или об отсутствии такой необходимости Минстрой России рекомендует принимать в момент принятия решения о включении (не включении) многоквартирного дома в региональную программу капитального ремонта (пункт 3 Методических рекомендаций). Данная рекомендация противоречит ЖК РФ в части установленного им порядка включения многоквартирных домов в региональные программы капитального ремонта (часть 2 статьи 168 ЖК РФ). Многоквартирный дом при действующем правовом регулировании организации капитального ремонта может быть включен в региональную программу лишь однажды. Более того, ЖК РФ вообще не связывает включение многоквартирного дома в программу капитального ремонта с фактом наличия необходимости в его капитальном ремонте или отсутствия этой необходимости - установленные условия для включения дома в программу не содержат такого критерия.

Таким образом, вышеуказанная рекомендация Минстроя России представляется невыполнимой. Возможно, что данную рекомендацию следует понимать следующим образом: «в момент принятия решения об актуализации региональной программы», поскольку в ходе такой актуализации формируется перечень многоквартирных домов, в которых будут выполняться работы по капитальному ремонту в очередной плановый период или в очередной календарный год. Лишь в таком контексте определение необходимости капитального ремонта общего имущества в многоквартирных домах имеет смысл, что подтверждает, в частности, часть 5 статьи 168 ЖК РФ, согласно которой региональная программа капитального ремонта подлежит актуализации не реже, чем один раз в год.

Анализ нормативных правовых актов, принятых субъектами Российской Федерации в целях регулирования порядка определения необходимости капитального ремонта, в целом позволяет говорить об единообразии подходов, применяемых регионами.

Так, наличие коллегиального органа (комиссии), создаваемого на постоянной основе либо временно, для принятия решения о необходимости проведения капитального ремонта является общим для подавляющего большинства субъектов Российской Федерации. При этом, Методические рекомендации предлагают такими полномочиями наделить орган, уполномоченный субъектом Российской Федерации на формирование и 
актуализацию региональной программы капитального ремонта (пункт 4), и лишь в спорных ситуациях прибегать к помощи соответствующей комиссии (пункт 6). Данная рекомендация была воспринята, к примеру, в Республике Адыгея [11], в которой комиссия создается лишь в спорных ситуациях. В Республике Бурятия [12] дополнительно к региональному уполномоченному органу создаются комиссии на уровне муниципалитетов. Комиссии на уровне муниципалитетов создаются также в Республике Марий Эл [13], Алтайском крае [14].

Круг субъектов, которые вправе инициировать вопрос о признании необходимости капитального ремонта, в регионах также не идентичен. В подавляющем большинстве регионов такими субъектами являются собственники помещений в многоквартирном доме, лица, осуществляющие управление многоквартирным домом, и организации, оказывающие услуги (выполняющие работы) по содержанию и текущему ремонту общего имущества в многоквартирном доме. В некоторых регионах инициировать вышеуказанный вопрос также могут органы местного самоуправления (Пермский край [15], Волгоградская область [16]), региональный оператор (Республика Башкортостан [17], Республика Карелия [18]), орган государственного жилищного надзора (Республика Бурятия, Республика Карелия), уполномоченный орган в сфере жилищно-коммунального хозяйства субъекта Российской Федерации (Пермский край).

Устанавливаемый субъектами Российской Федерации перечень документов, которые должен представить инициатор для решения вопроса о необходимости капитального ремонта, также варьирует от региона к региону. Подавляющее большинство регионов требуют для этого наличие заключения по результатам обследования и оценки технического состояния строительных конструкций и инженерных систем, входящих в состав общего имущества многоквартирного дома. Помимо указанного заключения для решения вопроса о необходимости в капитальном ремонте регионы также устанавливают заключение регионального оператора о достаточности средств фонда капитального ремонта для финансирования капитального ремонта (Республика Бурятия), заверенные управляющей организацией копии актов осмотра технического состояния общего имущества в многоквартирном доме (Волгоградская область), результаты мониторинга технического состояния многоквартирного дома (Белгородская область [19], Липецкая область [20]), акт органа регионального государственного жилищного надзора (Курганская область [21]).

В качестве оснований для принятия комиссией или уполномоченным органом решения о необходимости проведения капитального ремонта субъекты Российской Федерации устанавливают различные обстоятельства, среди которых можно привести следующие: достижение физического износа общего имущества в многоквартирном доме установленного федеральным законодательством уровня предельно допустимых характеристик надежности и безопасности (Республика Бурятия); выявленную опасность нарушения установленных предельных характеристик надежности и безопасности (Республика Марий Эл); ненадлежащее техническое состояние многоквартирного дома, конструктивных элементов и (или) инженерных систем многоквартирного дома (Красноярский край [22]).

Порядок установления необходимости капитального ремонта, принятый в некоторых субъектах Российской Федерации, кроме вышеперечисленных оснований принятия решений, предусматривает дополнительные активные действия со стороны уполномоченных комиссий. Так, в Республике Бурятия и Республике Марий Эл предусмотрен осмотр технического состояния конструктивных элементов и внутридомовых инженерных систем дома, который проводится комиссией с целью установления технического состояния общего имущества многоквартирного дома, требующего определения необходимости проведения капитального ремонта. В Курганской области комиссия наделена правом проводить выездные проверки визуального осмотра технического состояния общего имущества многоквартирного дома, требующего определения необходимости проведения капитального ремонта. В Рязанской области [23] аналогичные осмотры проводятся не комиссионно, а индивидуально должностным лицом уполномоченного органа. В Республике Башкортостан установление необходимости проведения капитального ремонта осуществляется в рамках процедуры внесения изменений в программу капитального ремонта.

В качестве заключения, сформулируем следующие выводы и предложения.

Проведенное исследование позволяет отметить в пределах Российской Федерации существенные региональные различия как по субъектам, обладающим правом инициировать вопрос об установлении необходимости капитального ремонта, так и по перечню документов, которые необходимо для этого представить. Полномочием по принятию решения о необходимости капитального ремонта, как правило, наделяются специальные комиссии, реже - орган исполнительной власти соответствующего субъекта Российской Федерации. В некоторых регионах решение о необходимости капитального ремонта принимаются и комиссией, и уполномоченным органом.

Критерии, которые используют в регионах в качестве основания для принятия решения о необходимости капитального ремонта, по своему содержанию в целом одинаковы и сводятся к оценке технического состояния 
многоквартирного дома (или его конструктивного элемента), в отношении которого принимается такое решение. Тем не менее, используемые некоторыми регионами формулировки допускают субъективный подход в таком вопросе. По нашему мнению, такая ситуация крайне нежелательна и требует вмешательства федерального законодателя по следующим направлениям:

- во-первых, критерии для принятия решения о капитальном ремонте и их значения предлагаем закрепить на федеральном уровне в целях обеспечения единообразного подхода при решении такого вопроса регионами. В противном случае, при одном и том же значении того или иного критерия могут быть приняты противоположные решения в зависимости от региона, в котором они принимаются. Такая ситуация может быть продемонстрирована наглядным примером, в котором результаты диагностики заболевания, являются основанием для принятия решения о необходимости оперативного вмешательства, и когда при идентичных результатах диагностики вопрос об оперативном вмешательстве решался бы в зави- симости от региона, в котором он принимается: в одних регионах операция требуется, в других нет;

- во-вторых, предлагаем максимально исключить возможность субъективной оценки при принятии решений о необходимости капитального ремонта. Выполнение работ по капитальному ремонту при условии отсутствия объективной необходимости в таких работах приведет к не эффективному расходованию денежных средств, уплаченных собственниками помещений соответствующего многоквартирного дома. При этом существенно возрастает роль мониторинга технического состояния многоквартирных домов, от результатов которого будет зависеть решение о необходимости капитального ремонта.

Выявленное противоречие положений Ведомственных строительных норм положениям ЖК РФ в части установленных ими предельных уровней физического износа требует устранения, которые мы предлагаем осуществить путем снижения установленного ЖК РФ уровня такого износа с $70 \%$ до $60 \%$.

\section{ЛИТЕРАТУРА}

1. Федеральный закон от 25.12.2012 № 271-Ф3 «0 внесении изменений в Жилищный кодекс Российской Федерации и отдельные законодательные акты Российской Федерации и признании утратившими силу отдельных положений законодательных актов Российской Федерации» // СЗ РФ. 2012 . № 53 (ч. 1). Ст. 7596.

2. Пункт 2 части 1 статьи 154 Жилищного кодекса Российской Федерации // СЗ РФ. 2005. № 1 (ч. 1). Ст. 14.

3. Часть 1 статьи 36 Жилищного кодекса Российской Федерации.

4. Пункт 14.2 статьи 1 Градостроительного кодекса Российской Федерации от 29.12.2004 № 190-Ф3 (в ред. от 18.07.2011) // С3 РФ. 2005. № 1 (ч. 1). Ст. 16. С3 РФ. 2011. № 30 (ч. 1). Ст. 4563.

5. Пункт 8.3 статьи 13 Жилищного кодекса Российской Федерации.

6. Приказ Минстроя России от 04.08.2014 № 427/пр «0б утверждении методических рекомендаций установления необходимости проведения капитального ремонта общего имущества в многоквартирном доме» // Бюллетень строительной техники. № 10.2014.

7. Утверждены приказом Госкомархитектуры при Госстрое СССР от 23.11.1988 № 312 // М., Стройиздат, 1990.

8. Утверждены приказом Госгражданстроя при Госстрое СССР от 24.12.1986 № 446.

9. ЖК РФ устанавливает такой вид работ как капитальный ремонт фасада. Расшифровку понятия «фасад» содержит Национальный стандарт Российской Федерации (ГОСТ Р 58033-2017), в котором под понятием главный фасад (facade) понимается одна из внешних стен здания, как правило, содержащая вход (пункт 5.2.44) - ГОСТ Р 58033-2017. Национальный стандарт Российской Федерации. Здания и сооружения. Словарь. Часть 1. Общие термины (Утв. и введен в действие Приказом Росстандарта от 19.12.2017 № 2031-ст) // М.: Стандартинформ, 2018.

10. Статья 1 Градостроительного кодекса Российской Федерации была дополнена пунктом 14.2, раскрывающим понятие «капитальный ремонт», незадолго до введения в действие новых правил о капитальном ремонте общего имущества в многоквартирных домах - Федеральный закон от 18.07.2011 № 215-Ф3 «0 внесении изменений в Градостроительный кодекс Российской Федерации и отдельные законодательные акты Российской Федерации» // С3 РФ. 2011. № 30 (ч. 1). Ст. 4563.

11. Постановление Кабинета Министров Республики Адыгея от 25.12 .2015 № 289 «0 Порядке установления необходимости проведения капитального ремонта общего имущества в многоквартирном доме» // Собрание законодательства Республики Адыгея. № 12, декабрь, 2015, ч. I.

12. Постановление Правительства Республики Бурятия от 07.10.2015 № 517 «0б утверждении Порядка установления необходимости проведения капитального ремонта общего имущества в многоквартирных домах на территории Республики Бурятия» // Официальный Интернет-портал Правительства Республики Бурятия www.egov-buryatia.ru.

13. Постановление Правительства Республики Марий Эл от 15.06 .2015 № 327 «0б утверждении Порядка установления необходимости проведения капитального ремонта общего имущества в многоквартирных домах на территории Республики Марий Эл» // Официальный интернет-портал Республики Марий Эл марийэл.рф. 
14. Постановление Администрации Алтайского края от 31.12.2014 № 599 «0б утверждении порядка установления необходимости проведения капитального ремонта общего имущества в многоквартирном доме» // Алтайская правда. № 10. 24.01.2015.

15. Постановление Правительства Пермского края от 24.04.2014 № 289-п «0б утверждении Порядка проведения мониторинга технического состояния многоквартирных домов, расположенных на территории Пермского края, и Порядка установления необходимости (отсутствия необходимости) проведения капитального ремонта общего имущества в многоквартирном доме» // Официальный интернет-портал правовой информации http://www.pravo.gov.ru.

16. Постановление Администрации Волгоградской обл. от 12.02.2018 № 59-п «0б утверждении Порядка установления необходимости проведения капитального ремонта общего имущества в многоквартирных домах, расположенных на территории Волгоградской области» // Официальный интернет-портал правовой информации http://www.pravo.gov.ru.

17. Постановление Правительства Республики Башкортостан от 31.10.2016 № 459 «0б утверждении некоторых нормативных правовых актов Республики Башкортостан в рамках реализации Закона Республики Башкортостан «0б организации проведения капитального ремонта общего имущества в многоквартирных домах, расположенных на территории Республики Башкортостан» и о признании утратившими силу некоторых решений Правительства Республики Башкортостан» // Официальный интернет-портал правовой информации http://www.pravo.gov.ru.

18. Постановление Правительства Республики Карелия от 08.07.2016 № 249-П «0б утверждении Порядка установления необходимости проведения капитального ремонта общего имущества в многоквартирном доме» // Официальный интернет-портал правовой информации http://www.pravo.gov.ru.

19. Постановление Правительства Белгородской обл. от 31.08.2015 N 318-пп «0б утверждении Порядка установления необходимости проведения капитального ремонта общего имущества в многоквартирных домах в Белгородской области» // Сайт «Вестник нормативных правовых актов Белгородской области» http://www.zakon.belregion.ru.

20. Постановление администрации Липецкой области от 05.08.2016 N 341 «0б утверждении Порядка установления необходимости проведения капитального ремонта общего имущества в многоквартирном доме» // Официальный интернет-портал правовой информации http://www.pravo.gov.ru.

21. Постановление Правительства Курганской области от 09.11.2015 N 348 «0б утверждении Порядка установления необходимости проведения капитального ремонта общего имущества в многоквартирном доме» // Официальный интернет-портал правовой информации http://www.pravo.gov.ru.

22. Постановление Правительства Красноярского края от 28.12.2015 № 725-п «0б утверждении Порядка установления необходимости проведения капитального ремонта общего имущества в многоквартирных домах, расположенных на территории Красноярского края» // Официальный интернет-портал правовой информации Красноярского края http://www.zakon.krskstate.ru.

23. Постановление Правительства Рязанской области от 16.03.2016 N 47 «06 определении Порядка установления необходимости проведения капитального ремонта общего имущества в многоквартирном доме» // Официальный интернет-портал правовой информации http://www.pravo.gov.ru.

○ Картавов Сергей Александрович (kartavovs@yandex.ru), Сидоров Юрий Вадимович (yuriy.sidorov@ui.ranepa.ru).

Журнал «Современная наука: актуальные проблемы теории и практики»

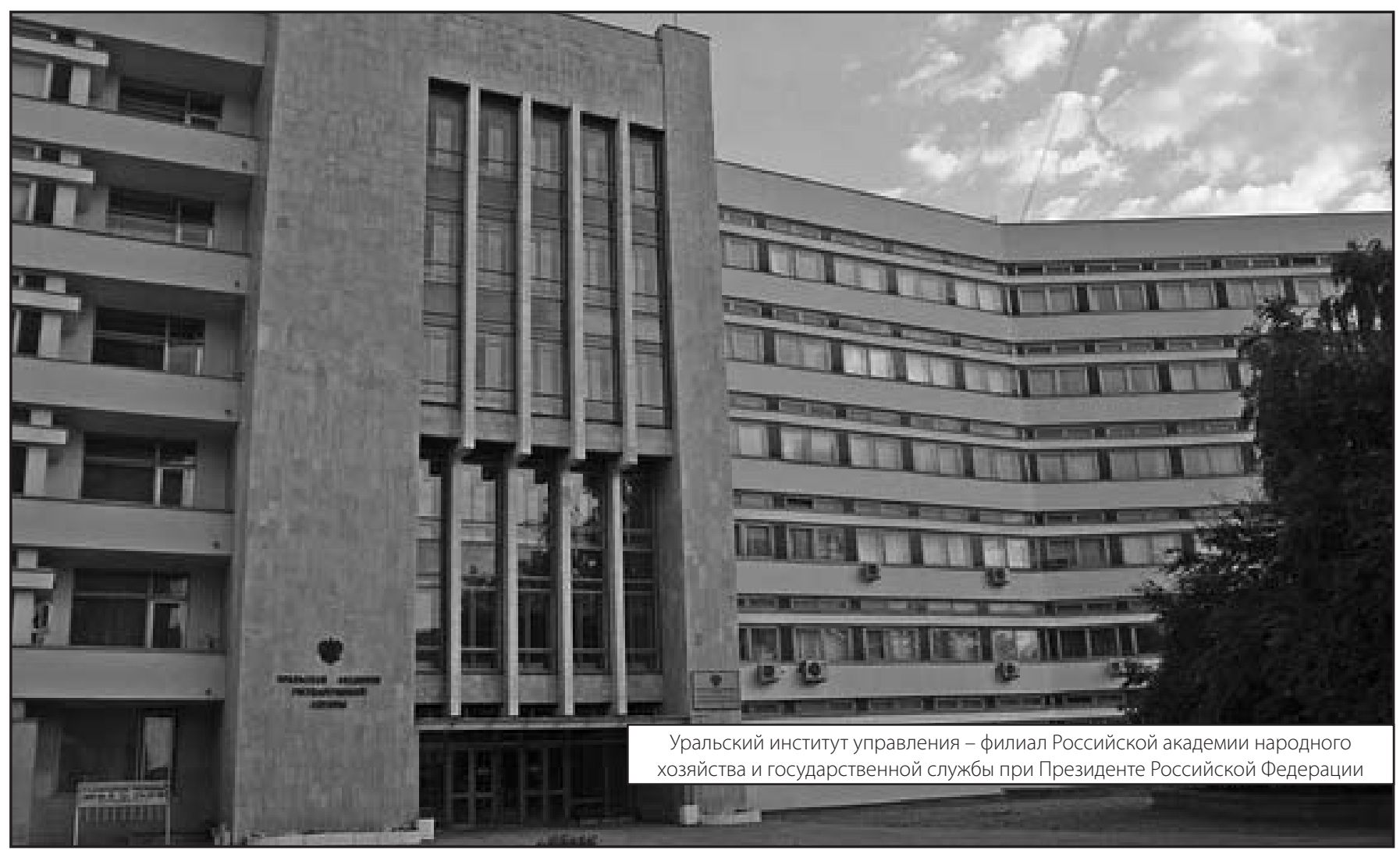

